\title{
Congresso Internacional de Atividade Físi- ca e Saúde Pública: Atlanta, Amsterdam, Toronto, Sydney, próxima parada, Rio de Janeiro, Brasil
}

Rev Bras Ativ Fis Saúde p. 331

DOI: http://dx.doi.org/10.12820/2317. 1634.2012v17n5p331

1 Escola de Saúde e Biociências, Pontifícia Universidade Católica do Paraná, Curitiba, $P R$, Brasil.

2 Departamento de Educação Física, Universidade Federal do Paraná, Curitiba, $P R$, Brasil.

Rodrigo Siqueira Reis ${ }^{1}$

De 8 a 11 de Abril de 2014, o Rio de Janeiro será a capital mundial da área de atividade física e saúde. Após o primeiro evento em Atlanta (EUA) em 2006, e após paradas em Amsterdam (Holanda, 2008), Toronto (Canadá, 2010) e Sydney (Austrália, 2012), o Congresso Internacional de Atividade Física e Saúde Pública finalmente será realizado fora do circuito dos países de alta renda. E o privilégio de sediá-lo não poderia ser de outro país de renda média ou baixa que não o Brasil. É com muito orgulho que o Brasil hoje é um dos líderes mundiais na pesquisa em atividade física e saúde, situação infelizmente diferente de outras áreas do conhecimento relacionadas à Educação Física, nas quais a pesquisa brasileira ainda engatinha no cenário internacional.

$\mathrm{Na}$ verdade, na área de atividade física e saúde, o Brasil está à frente da comunidade internacional em muitos aspectos; nosso congresso, nossa revista e nossa sociedade científica são mais antigos do que suas versões internacionais. Na quarta edição do evento, em Sydney, mais de 25 pesquisadores brasileiros atravessaram oceanos e deram visibilidade a pesquisa de ponta realizada no país. Nossos pesquisadores não apenas apresentaram trabalhos orais e pôsteres mas estiveram presentes em várias mesas de discussão como convidados e ainda foram finalistas dos melhores trabalhos do evento.

Agora é chegada a hora de receber os pesquisadores do mundo todos em nossas terras e oportunizar a muitos colegas que não podem se deslocar para outros países a oportunidade de conviver, trocar informações e explorar parcerias com os maiores nomes do mundo na área de atividade física e saúde. Ainda mais ímpar será a oportunidade para os alunos de graduação e pós-graduação do Brasil que poderão pela primeira vez conhecer colegas e pesquisadores que em muitos casos somente são conhecidos por livros e artigos.

A comunidade da área de atividade física e saúde do Brasil vive um momento auspicioso sem dúvida mas também tem à sua frente um grande desafio. $\mathrm{O}$ nosso país ainda é um dos mais desiguais do mundo e milhões de pessoas pelo Brasil a fora vivem em condições que fazem a atividade física um comportamento necessário para a subsistência mas não desfrutam a oportunidade para momento ativos seja no lazer ou no transporte. Ao receber o congresso internacional nós temos também a oportunidade de avançar o olhar internacional sobre o problema de inatividade física no mundo em desenvolvimento o que será um marco histórico para a área.

Que venha o congresso internacional em 2014 e com ele mais uma oportunidade de apresentar a contribuição de nossa comunidade de pesquisadores para a atividade física e saúde no mundo. 